QUALITY IMPROVEMENT REPORT

\title{
Use of a preprinted sticker to improve the prescribing of prophylactic antibiotics for hip fracture surgery
}

\author{
S Ritchie, N Scanlon, M Lewis, P N Black
}

Qual Saf Health Care 2004;13:384-387. doi: 10.1136/qshc.2003.009696

See end of article for authors' affiliations

西

Correspondence to: Dr S Ritchie, Medical Registrar, Auckland Hospital, Private Bag 92014, Auckland; sritch@ adhb.govt.nz

Accepted for publication 11 July 2004
Problem: Antibiotic prophylaxis has been shown to reduce the number of postoperative infections following surgery for hip fracture. At Auckland Hospital the policy for antibiotic prophylaxis for hip fracture surgery is for the patient to receive the first dose of antibiotic at the induction of anaesthesia followed by two more doses at 8 hour intervals. A previous audit found that patients often received too many doses of antibiotic. A retrospective audit was performed of 100 patients undergoing surgery for a hip fracture. The primary problem was over-prescribing; 68 patients $(68 \%)$ received more than three doses. The number of patients who received three doses according to the guidelines was $29129 \%, 95 \% \mathrm{Cl}$ 21 to 40$)$.

Setting: Auckland Hospital which provides acute orthopaedic services for a population of 500000 .

Strategy for change: A sticker was introduced with the prescription printed on it. The sticker was applied to the medication chart by the anaesthetist when the initial dose of antibiotic was given. Charts of a further 100 patients were reviewed after the introduction of the sticker and compared with those from another hospital in Auckland where the sticker was not used.

Effects of change: The number of patients who received three doses, in accordance with the guidelines, improved to $74(74 \%, 95 \% \mathrm{Cl} 64$ to $82, \mathrm{p}<0.001)$. These changes were observed even though the sticker was only used in 44 patients $(44 \%, 95 \% \mathrm{Cl} 34$ to 54$)$. At the other hospital the number of patients who received three doses was $10(20 \%, 95 \% \mathrm{Cl} 10$ to 42$)$ and $13(26 \%, 95 \% \mathrm{Cl} 15$ to $40, \mathrm{p}=0.37)$ for the same two periods.

Lessons learnt: The use of a preprinted sticker is a simple intervention which improves the use of antibiotic prophylaxis at the time of surgery. This improvement occurred even though the sticker was used in slightly fewer than half the cases.
A ntibiotic prophylaxis is recommended for a wide variety of potentially contaminated surgical procedures and for some "clean" procedures, especially when a prosthetic device is implanted. A systematic review found that the use of antibiotic prophylaxis in the operative repair of closed neck of femur fractures was effective in reducing postoperative infections. ${ }^{1}$ The relative risk for deep wound infection was 0.36 (95\% CI 0.21 to 0.65 ) when multiple dose antibiotic prophylaxis was compared with placebo or no treatment. ${ }^{1}$ The first dose should be administered no more than 2 hours before the initial surgical incision. ${ }^{2}$ The optimal duration of antibiotic prophylaxis remains controversial. In hip fracture repair there is evidence to support both the use of a single dose given at induction ${ }^{3}$ and for continuing the antibiotics for a total of 24 hours. ${ }^{1}$ It is not clear if one approach is better than the other; a meta-analysis showed a relative risk for deep wound infection of 0.4 (95\% CI 0.24 to $0.67)$ when single dose prophylaxis was compared with placebo or no treatment. ${ }^{1}$

The administration of antibiotic prophylaxis at the time of surgery is a frequent cause of prescription errors. ${ }^{4}$ Previous reports have identified numerous problems including poor timing, poor documentation, the use of inappropriate antibiotics, and the use of too few or too many doses.-6 These reports found that compliance with antibiotic guidelines before intervention was $32 \%$ in orthopaedic, obstetric and gynaecological and general surgery ${ }^{4}$ and $17 \%$ in orthopaedic surgery. ${ }^{6}$

\section{BACKGROUND AND SETTING}

At Auckland Hospital the policy for surgical fixation of a closed fracture of the neck of the femur is to give $1 \mathrm{~g}$ of cephazolin at induction of anaesthesia and no more than 2 hours before the first incision. A further two doses are given at 8 hourly intervals so that the patient receives a total of three doses in 24 hours.

Before our intervention there were few systems in place to ensure adherence to these guidelines. The anaesthetists gave the initial dose at induction and this prescription, including the time of administration, was recorded on the anaesthetic record. When the patient left the operating room there was often no prescription for the remaining two doses in the medication chart. The house officer was usually asked by the nursing staff to write the prescription for the remaining doses. He/she might prescribe three doses of antibiotic if there was a failure to appreciate that the first dose was given in the operating room. On other occasions an open ended prescription could be written and the patient would receive more than three doses of antibiotic after returning to the ward.

\section{OUTLINE OF THE PROBLEM}

The drug utilisation and evaluation (DUE) pharmacist found, in an earlier audit some years ago, that the most common error was for too many doses to be prescribed. This increases the risk of adverse effects, prolongs the time with intravenous access in situ, and may contribute to the development of antibiotic resistance and lead to unnecessary expenditure on medicines and nursing time.

\section{DESIGN OF STUDY}

The first step was to define the problem by way of an audit. We determined the number of patients who received a total 
Table 1 Results for the study hospital

\begin{tabular}{|c|c|c|}
\hline & $\begin{array}{l}\text { Before intervention } \\
(\mathrm{n}=100)\end{array}$ & $\begin{array}{l}\text { Following intervention } \\
(n=100)\end{array}$ \\
\hline $\begin{array}{l}\text { Median (range) age } \\
\text { (years) }\end{array}$ & $83(16-102)$ & 83 (39-99) \\
\hline Female (\%) & 74 (64 to 82 ) & 80 (71 to 87$)$ \\
\hline $\begin{array}{l}\text { Cephazolin at induction } \\
\text { (\%) }\end{array}$ & 99 (95 to 100$)$ & $98(93$ to 100$)$ \\
\hline $\begin{array}{l}\text { Cephazolin } \\
\text { postoperatively (\%) }\end{array}$ & $98(93$ to 100$)$ & 97 (92 to 99) \\
\hline$<2$ doses & $2(0$ to 11$)$ & $8(4$ to 15$)$ \\
\hline 2 doses & $30(21$ to 40$)$ & $76(66 \text { to } 84)^{*}$ \\
\hline$>2$ doses & 68 (58 to 78$)$ & $16(10 \text { to } 26)^{*}$ \\
\hline $\begin{array}{l}\text { Cephazolin } 3 \text { doses in } \\
\text { total as per policy (\%) }\end{array}$ & 29 (21 to 40$)$ & $74(64 \text { to } 82)^{*}$ \\
\hline Sticker used (\%) & Not applicable & 44 (34 to 54$)$ \\
\hline
\end{tabular}

of three doses of antibiotics, with the first dose being given at the time of induction.

\section{Patients}

Patient records were identified by a search of the hospital coding database. Patients with fractured neck of femur (ICD codes S7200-S7208) as a primary or secondary diagnosis were included in the study. Those receiving antibiotics as part of their treatment (open fractures or more extensive trauma) and those who did not have an opportunity to receive antibiotic prophylaxis according to the policy (for example, no operation was performed, the patient was moved to another healthcare facility in the 24 hour period after the operation, or the patient died within 24 hours of the operation) were excluded. The notes of 100 consecutive patients were examined from January 1999.

\section{Measurements}

The age and sex of the patients and the number of cephazolin doses given intraoperatively and postoperatively were recorded. When patients received other antibiotics perioperatively we recorded the antibiotic, dose, and indication.

\section{Analysis and interpretation}

The anaesthetic records showed that 99 patients (99\%) received antibiotics during the 2 hours before surgery (table 1). No patient received more than one dose intraoperatively. In contrast, only 30 patients $(30 \%)$ received two doses postoperatively; two patients $(2 \%)$ received no doses postoperatively, while the remaining 68 patients $(68 \%)$ received more than two doses. The two patients who did not receive cephazolin postoperatively were treated with another antibiotic for a concomitant lower respiratory tract infection.

This audit confirmed our suspicion that the primary problem was overprescribing with only $29 \%$ of patients receiving three doses of antibiotics in accordance with the guidelines. This appears to have been due to failure to follow

\begin{tabular}{|l|l|l|l|}
\hline $\begin{array}{l}\text { Antimicrobial Prophylaxis Protocol } \\
\text { FOLLOWING Orthopaedic Procedures }\end{array}$ \\
\hline Cephazolin & $1 \mathrm{~g}$ & $\mathrm{IV}$ & $\begin{array}{l}\mathrm{Q} 8 \text { hourly } \times 2 \\
\text { doses }\end{array}$ \\
\hline $\begin{array}{l}\text { (Antimicrobial prophylaxis duration }=24 \text { hour } \\
\text { total as initial cephazolin dose administered on } \\
\text { anaesthetic induction) }\end{array}$ \\
\hline
\end{tabular}

Figure 1 Sticker applied to medication chart. the guidelines rather than to clinical need. No patient had antibiotic therapy continued for clinical indications such as wound infection.

\section{STRATEGIES FOR CHANGE AND IMPROVEMENT}

Traditionally, the surgeon has been responsible for the initiation and prescription of antibiotic prophylaxis. The DUE pharmacist presented the results of the audit to the director of orthopaedic surgery who then met with the surgeons to discuss the concerns raised. The surgeons were keen to improve antibiotic delivery while remaining ultimately responsible for antibiotic prophylaxis.

One approach to the problem would be to have additional teaching sessions for the orthopaedic house officers. This approach would require the need to repeat the sessions every 3 months with each new rotation. Some of the house officers may not attend these sessions because of duties elsewhere and the nursing staff would still have to prompt the house officers to write each prescription.

We therefore developed a preprinted sticker (fig 1) on which the dose of cephazolin, dose interval ( 8 hourly) and the duration (two doses) were printed for use once the patient had returned from the operating theatre. The use of the sticker was discussed during a meeting between representatives from the pharmacy and the orthopaedic surgeons and received unanimous support. They agreed with our approach to involve the anaesthetists who are well placed to help with improving antibiotic prophylaxis. The most important antibiotic dose is that given by the anaesthetist at induction $^{2}$ and our audit showed that this dose was delivered appropriately and consistently.

In June 1999 a group of pharmacists met with the anaesthetists to outline the sticker usage. The anaesthetists were asked to apply the sticker to the medication chart and to sign it once the first intraoperative dose had been given. The stickers were readily available in the operating rooms and in the recovery area from that time onwards. The anaesthetic department made sure that all of the anaesthetists were informed about the sticker. They were not informed of the audit and did not receive additional reminders to use the sticker. The anaesthetists were involved in the study only after consultation with the orthopaedic surgeons; both parties agreed that responsibility for initiation of antibiotic prophylaxis at induction of anaesthesia would be delegated to the anaesthetists.

\section{ANALYSIS OF IMPROVEMENT}

The audit was repeated on 100 consecutive patients from September 1999 following the introduction of the sticker. Patients were selected using the same criteria as in the first audit. To control for changes that may have occurred over

Table 2 Comparison of subjects for whom the sticker was and was not used

\begin{tabular}{|c|c|c|}
\hline & $\begin{array}{l}\text { Sticker used } \\
(n=44)\end{array}$ & $\begin{array}{l}\text { Sticker not used } \\
(n=56)\end{array}$ \\
\hline Median (range) age (years) & $82(54-97)$ & 83 (39-99) \\
\hline Female (\%) & $80(65$ to 90$)$ & $80(68$ to 90$)$ \\
\hline Cephazolin at induction (\%) & $98(88$ to 100$)$ & $98(90$ to 100$)$ \\
\hline $\begin{array}{l}\text { Cephazolin postoperatively } \\
(\%)\end{array}$ & $98(88$ to 100$)$ & $96(88$ to 100$)$ \\
\hline$<2$ doses & $9(3$ to 22$)$ & $7(2$ to 17$)$ \\
\hline 2 doses & 82 (67 to 92 ) & 71 (58 to 83$)$ \\
\hline$>2$ doses & $9(3$ to 22$)$ & 21 (12 to 34$)$ \\
\hline $\begin{array}{l}\text { Cephazolin } 3 \text { doses in total } \\
\text { as per policy (\%) }\end{array}$ & $80(65$ to 90$)$ & $70(56$ to 81$)$ \\
\hline \multicolumn{3}{|c|}{$\begin{array}{l}\text { Results are shown as percentages with } 95 \% \text { confidence intervals. Nc } \\
\text { differences were statistically significant. }\end{array}$} \\
\hline
\end{tabular}


time and that were unrelated to the intervention, data were also collected from 50 patients from another hospital in Auckland for each of the two time periods. These patients were identified in the same way and the same exclusion criteria were used. The two orthopaedic departments are of similar size and serve similar populations and have the same policy regarding antibiotic prophylaxis for repair of fractured neck of femur.

Fisher's exact test for $2 \times 2$ tables was used to examine for statistical significance before and after sticker initiation at each hospital. The Mantel-Haenszel test was used to compare the results in the two hospitals.

\section{EFFECTS OF CHANGE}

The sticker was only used in 44 cases (44\%). Despite this low usage, there was a significant improvement in compliance with antibiotic policy. Before the sticker was available, only 29 patients $(29 \%$ (95\% CI 21 to 40$)$ ) received the correct antibiotic prophylaxis which improved to 74 patients $(74 \%$ (95\% CI 64 to 82 ), p<0.001) after introduction of the sticker (table 1 ).

This improvement was seen in all patients, not only those for whom the sticker was used (table 2); 35 of the 44 patients for whom the sticker was used ( $80 \%$ (95\% CI 65 to 90)) had antibiotic prophylaxis according to the guidelines while 39 of the 56 patients who did not have the sticker attached to their chart (70\% (95\% CI 56 to 81$)$ ) received the correct antibiotic regime $(p=0.1869)$. There was a significant improvement irrespective of whether or not the sticker was used.

Excessive doses were given to nine patients even though the sticker was used. The pharmacy department and senior nursing staff are agreed that the sticker is clear and further education of the nursing staff has been undertaken.

At the control hospital where the sticker was not used, there was little change over the two time periods. The number of patients receiving a total of three doses of cephazolin was $10(20 \%$ (95\% CI 10 to 42$))$ in the first time period and $13(26 \%$ (95\% CI 15 to 40$))$ in the second time period $(p=0.32$, table 3$)$. In the second time period the proportion of patients receiving cephazolin at induction actually declined from $48(96 \%)$ to $40 \quad(80 \%) \quad(p<0.001$, table 3). At baseline the prescribing of cephazolin at the two hospitals was similar, as were the characteristics of the subjects. In the second time period, however, there was a clear difference between the two hospitals in antibiotic use: 13 patients $(26 \%)$ at the control hospital received the appropriate number of doses compared with 74 patients (74\%) at the study hospital; the $95 \%$ confidence intervals did not overlap.

Table 3 Results for the control hospital

\begin{tabular}{|c|c|c|}
\hline & $\begin{array}{l}\text { Before } \\
\text { intervention } \\
(n=50)\end{array}$ & $\begin{array}{l}\text { Following } \\
\text { intervention } \\
(n=50)\end{array}$ \\
\hline $\begin{array}{l}\text { Median (range) age (years) } \\
\text { Female (\%) } \\
\text { Cephazolin at induction (\%) } \\
\text { Cephazolin postoperatively (\%) } \\
<2 \text { doses } \\
2 \text { doses } \\
>2 \text { doses } \\
\text { Cephazolin } 3 \text { doses in } \\
\text { total as per policy (\%) }\end{array}$ & $\begin{array}{l}85(13-103) \\
68(53 \text { to } 80) \\
96(86 \text { to } 100) \\
98(89 \text { to } 100) \\
2(0 \text { to } 7) \\
18(9 \text { to } 31) \\
80(66 \text { to } 90) \\
20(10 \text { to } 42)\end{array}$ & $\begin{array}{l}82(45-105) \\
64(49 \text { to } 77) \\
80(66 \text { to } 90)^{*} \\
96(86 \text { to } 100) \\
6(1 \text { to } 17) \\
10(3 \text { to } 22) \\
84(70 \text { to } 93) \\
26(15 \text { to } 40)\end{array}$ \\
\hline
\end{tabular}

\section{LESSONS LEARNT}

In our institution the guidelines recommend the use of three doses of cephazolin over 24 hours with the first dose being given before incision. The main problem was the use of an excessive number of doses. Before our intervention, only $29 \%$ of patients received antibiotic prophylaxis according to the guidelines. Gyssens et al ${ }^{4}$ found that implementing clear guidelines improved compliance with antibiotic prophylaxis, but the easy availability of guidelines in our hospital had not resolved these problems. We therefore introduced the sticker and the number of patients who received the correct number of doses increased to $74 \%$.

The sticker was only used in $44 \%$ of operations; the house officers were responsible for prescribing the remaining doses for the other patients once they had returned to the ward. Nonetheless, as the junior medical staff became familiar with the sticker, it may have prompted them to prescribe the appropriate number of doses in the other patients and this may also have led to an improvement in antibiotic use. We plan to have further discussions with the orthopaedic surgeons and to make the sticker available on the orthopaedic wards, as well as in the operating rooms and theatre recovery, in an attempt to further improve antibiotic use.

We had only one meeting with the anaesthetists and use of the sticker was entirely up to each individual. None of the anaesthetists expressed any concern regarding use of the sticker. With the benefit of hindsight, improved uptake of the sticker might have occurred had we held further meetings with the anaesthetists and asked the operating theatre pharmacists to provide ongoing reminders and support. We expect that usage of the sticker will have improved after feedback of the results of this study to the anaesthetic department.

\section{CONCLUSION}

A reduction in the number of unnecessary doses of antibiotic was achieved. This has a number of benefits including cost saving which relates not only to the cost of the antibiotic itself but also to the other costs associated with the administration of intravenous antibiotics including nursing time. Short courses of antibiotics increase the incidence of colonisation by resistant organisms. Burnett et al found that, after 72 hours of cephalothin prophylaxis for surgical repair of hip fractures, $42 \%$ of positive cultures from all sites grew cephalothin resistant organisms. Other studies have reported similar findings. ${ }^{8}$ Any intervention that limits the unnecessary prolongation of antibiotic treatment should reduce the development of antibiotic resistance.

The use of a sticker is simple, inexpensive, easily implemented, and leads to an improvement in the use of

\section{Key messages}

- Antibiotic prophylaxis reduces postoperative infections in hip fracture surgery but the antibiotics are not always given appropriately.

- A majority of patients received too many doses of prophylactic antibiotic.

- The introduction of a preprinted sticker attached to the medication chart led to a significant improvement in the use of antibiotic prophylaxis.

- This intervention is cheap, simple, and easy to implement. 
prophylactic antibiotics for the repair of hip fractures. This approach may also be useful for the prescribing of prophylactic antibiotics for other types of surgical procedure.

\section{ACKNOWLEDGEMENTS}

The authors thank Greg Gamble (Department of Medicine, University of Auckland) for help with the statistical analysis, E Malcolm and L Britton (Pharmacy, Middlemore Hospital) for help with the audit, and the orthopaedic surgeons, anaesthetists and clinical pharmacists at Auckland Hospital for their support of this project.

\section{Authors' affiliations}

S Ritchie, P N Black, Department of Medicine, Auckland Hospital, Auckland, New Zealand

N Scanlon, Department of Pharmacy, Auckland Hospital, Auckland, New Zealand

M Lewis, Department of Pharmacy, Middlemore Hospital, Auckland, New Zealand

\section{REFERENCES}

1 Gillespie WJ, Walenkamp G. Antibiotic prophylaxis for proximal femoral and other closed long bone fractures. Cochrane Database Syst Rev Issue 3, 2002.

2 Classen DC, Evans RS, Pestotnik SL, et al. The timing of prophylactic administration of antibiotics and the risk of surgical-wound infection. N Engl J Med 1992;326:281-6.

3 Boxma $\mathrm{H}$, Broekhuizen T, Patka P, et al. Randomised controlled trial of singledose antibiotic prophylaxis in surgical treatment of closed fractures: the Dutch trauma trial. Lancet 1996;347:1133-7.

4 Gyssens IC, Geerligs EJ, Dony MJ, et al. Optimising antimicrobial drug use in surgery: an intervention study in a Dutch university hospital. J Antimicrob Chemother 1996:38:1001-12.

5 Mutuschka PR, Burke JD, Cheadle WG, et al. Improving the timing and documentation of antibiotics administered for surgical prophylaxis. Hosp Pharm 1998;33:293-6.

6 Mottram MC, Pearce MJ, Allen B, et al. Effect of therapeutic guidelines on surgical antibiotic prophylaxis. Aust J Hosp Pharm 1997:27:290-5.

7 Burnett JW, Gustilo RB, Williams DN, et al. Prophylactic antibiotics in hip fractures. J'Bone Joint Surg 1980;62-A:457-61.

8 Kernodle DS, Barg NL, Kaiser AB. Low-level colonization of hospitalized patients with methicillin-resistant coagulase-negative staphylococci and emergence of the organisms during surgical antimicrobial prophylaxis. Antimicrob Agents Chemother 1988;32:202-8. 